\title{
Out of Africa? The logic of phoneme inventories and founder effects
}

\author{
CLAIRE BOWERN
}

\section{Introduction}

Atkinson (2011) discusses a tantalizing result, that phoneme inventory size may reflect a set of population expansions out of Africa tens of thousands of years ago. The starting point for the article is a correlation, first noted in Hay $\&$ Bauer 2007, that inventory size is positively correlated with population size. Atkinson shows that inventory size, as measured by a combination of features based on WALS data (Haspelmath et al. (eds.) 2008), declines as distance from Africa increases, even controlling for population size. He attributes this correlation to serial founder effects.

As appealing as such results may seem at first glance, there are both methodological and conceptual problems with the study. In this commentary, I focus on the role of founder effects and their relation to phoneme inventory size, causes of inventory expansion and contraction, and what we know about founder events in recorded history. In sum, I argue that founder effects do not apply at the level of the phoneme, that we have no data on whether population correlations hold within small groups, and that the current distribution of languages, for most of the world, reflects Holocene rather than Pleistocene expansions.

\section{Holocene expansions}

First, it is an obvious but nonetheless important point to make that all of the largest language families in the present world are the result of expansions in the Holocene period (that is, within the last 10,000 years). Austronesian, Bantu, Tupí, Algonquian, Pama-Nyungan, Sino-Tibetan, Turkic, and Indo-European are all dated to within the last 5,000 to 8,000 years. ${ }^{1}$ At least half of the world's

1. References for these dates are well established in the literature with the exception of Pama- 
currently spoken languages are the descendants of families which are known to be recent expansions. Therefore, whatever the current distribution of languages, such a distribution is very unlikely to represent Pleistocene distributions. Holocene expansions in Africa, Asia, the Americas, Australia, and Europe have obliterated the languages which were spoken there before. Atkinson attempts to control for this by examining dispersals of a few families which are known to have colonized areas since the Last Glacial Maximum. This ignores the fact, however, that there have been considerable spreads even in areas which were inhabited before the Last Glacial Maximum. There is also no evidence, for the most part, that current families represent the expansions of the first populations into those areas uninhabited since the Last Glacial Maximum. Atkinson's language location samples are thus strongly biased towards Holocene spreads and cannot be used to investigate the distribution of linguistic features in earlier periods.

\section{Population sizes, founder effects, and bottlenecks}

Atkinson concentrates on founder effects as a means of explaining correlations between small populations and small phoneme inventory sizes. However, founder effects are not the only cause of loss of genetic diversity. There are also demographic bottlenecks. Humans are known to have undergone several such bottlenecks, even within the last 10,000 years. For example, the Plague of Justinian in the sixth to eighth centuries is estimated to have reduced world populations by up to $50 \%$ (Ackerknecht 1965), and the Black Death and Great Famine of the fourteenth century probably reduced Eurasia's population by about one third. Such events reduce genetic diversity and should be reflected in Atkinson's linguistic diversity sample as well, assuming that a founder effects model holds. That is, the processes which reduce diversity in genetics are more broad than founder effects caused by migration, and are found in other contexts as well. If the same mechanism that produces founder effects in genetics is responsible for linguistic founder effects, we should expect to see linguistic effects in more recent population bottlenecks; but we do not.

Atkinson uses current population figures (from the Ethnologue; Lewis (ed.) 2009). Such figures are skewed in two directions. Firstly, they systematically underestimate historical populations which have suffered as a result of colonial expansions; most of these languages are in the regions furthest from Africa. In Australia, for example, the indigenous population in 1920 was just $10 \%$ of that of a hundred years before (Briscoe \& Smith (eds.) 2002). Comparable population declines are reconstructed in the New World following European settle-

Nyungan, which is based on work in progress (though consistent with other work, such as McConvell 1996 and Hale 1964, 1976). Other references for family dates include: IndoEuropean: Mallory 1989; Austronesian: Gray et al. 2009; Bantu: Holden 2002. 
Table 1. Variation in phoneme inventory size (Mielke 2008)

\begin{tabular}{lcccccc}
\hline Family & $\begin{array}{c}\text { Languages } \\
\text { in } \\
\text { sample }\end{array}$ & $\begin{array}{c}\text { Average } \\
\text { inventory } \\
\text { size }\end{array}$ & Minimum & Maximum & Range & $\begin{array}{c}\text { Standard } \\
\text { deviation }\end{array}$ \\
\hline Pama-Nyungan & 153 & 24 & 16 & 58 & 42 & 6 \\
Niger-Congo & 118 & 36 & 17 & 75 & 58 & 13 \\
Indo-European & 82 & 41 & 24 & 78 & 54 & 10 \\
Austronesian & 55 & 23 & 15 & 47 & 32 & 7 \\
Mixe-Zoque & 22 & 23 & 18 & 33 & 15 & 6 \\
Sino-Tibetan & 21 & 33 & 20 & 50 & 30 & 10 \\
Nilo-Saharan & 18 & 35 & 23 & 53 & 30 & 8 \\
Trans-New-Guinea & 18 & 19 & 14 & 26 & 12 & 3 \\
Dravidian & 17 & 34 & 25 & 54 & 29 & 8 \\
Uto-Aztecan & 15 & 25 & 18 & 34 & 16 & 4 \\
\hline
\end{tabular}

ment. Conversely, population increases in the last two hundred years (and especially in the last fifty) have been concentrated in areas populated by speakers of Indo-European and Sino-Tibetan, and to a lesser extent Niger-Congo languages. Thus not only are language family distributions not reflective of more than the last few thousand years; the population estimates are not reflective of situations of more than 1,000 years, and are distorted in several directions.

Founder effects in genetics are robust because of the time it takes for genetic diversity to recover after a bottleneck (Chakraborty \& Nei 1977). In contrast, linguistic change is much more rapid. We have long known this (see, for example, Hock \& Joseph 1996). The comparative method has a time horizon of roughly ten thousand years because of the combined effects of lexical and sound change. Even if certain lexical items are quite stable and may last for millennia in languages, such items are not immune from sound change and so may become unidentifiable (that is, the patterns may still be regular but because of lexical change there are not enough examples of such patterns to discern the regularity). Within families, variation in phoneme inventory size is substantial; figures of ten of the largest language family samples in Mielke 2008 are given in Table $1 .^{2}$ As can be seen, there is substantial variation in families of even quite shallow time depth; this is brought out in data showing absolute numbers of phonemes, rather than the ranges that Atkinson uses in his dataset. Hunley et al. (in preparation) provide evidence that the mutation rate within families is sufficiently high to be inconsistent with a founder effects model.

2. See also Choudhury et al. 2009 for a formal model of this diversity. 


\section{Founder effects in language}

Perhaps the most crucial problem with the idea that phoneme inventory size reflects population expansion from Africa is the unit of analysis. Atkinson has systematically confused phonetic and phonological diversity. Founder effects in linguistics, if they exist, would apply at the level of sub-phonemic variation, not phoneme inventory size. The basis of Atkinson's model is given as follows (2011: Supporting Online Material: 3): "Under this model, during population expansion small founder groups are expected to carry less PHONEMIC [emphasis mine; $\mathrm{CB}$ ] diversity than their larger parent populations. A series of founder events should produce a gradient of decreasing phonemic diversity with increasing distance from the origin." And further (Atkinson 2011: Supporting Online Material: 8) "The same scenario can apply to PHONEMIC [emphasis mine; $\mathrm{CB}$ ] diversity if founder populations sometimes sample only a subset of phonemes from the parent population (e.g., from a dialect of the parent language) or are likely to lose phonemes during the subsequent population bottleneck."

There are numerous problems with this formulation. First, dialectal diversity (that is, diversity conditioned by geography) is only one type of internal linguistic diversity. Diversity can be conditioned by many factors, including age, gender, social category (class, clan, caste, or phratry; see Stanford \& Preston (eds.) 2009). Crucially, however, this diversity is to be found mostly at the PHONETIC level and not at the phonemic level. It is true that varieties of languages (whether geographically conditioned variation or other variation is considered) do vary in the number of phonemes they exhibit. But this variation is small. Among the 38 languages in Mielke's (2008) database which have representatives of more than one geographic dialectal variety, the mean variance in phoneme size is 2.5 phonemes, with a range from 0 to 20 and standard deviation of 4.17. Arabic shows the largest range of variation, with 20 phonemes (inventory size ranging from 31 to 51 items); Arabic would not normally be classed as a single "language" by linguists since the varieties are mutually unintelligible.

A much greater range of variation is found at the subphonemic level. This is what drives sound change (for discussion on this topic see, amongst others, Labov 2001, 2007; Garrett \& Johnson (forthcoming); Ohala 2009) and is the area of linguistics in which we might expect founder effects to apply. Put in biological terms, phonemes are the equivalent of genes, and allophones are alleles, i.e., alternative forms of those genes. In genetic founder effects, allele frequency diminishes, but not gene frequency. Assuming a founder effect where a small group of speakers split off from the main population, if they are speaking the same language, we would expect them to have approximately the 
same number of phonemes. We would also expect them to exhibit a subset of the variation present in the language as a whole.

The relationships between population size and degree of internal variation in a community is a contentious issue. While for the most part, smaller communities have less variation (see Milroy \& Milroy 1992 and others), there are counterexamples (Dorian 1994 and Bowern 2008 discuss two, in East Sunderland Gaelic and eastern Arnhem Land respectively). More generally, small populations are expected to exhibit slower rates of change, because small communities tend to have dense and multiplex social networks, and such network structures are known to impede both social and linguistic change (Granovetter 1983; Milroy 1992; Milroy \& Milroy 1985, 1992). Such observations also underlie Trudgill's (2004a, b) explanations of correlations between phoneme inventory sizes and population sizes. Atkinson makes reference to simulations by Nettle $(1999,2000)$, but Nettle's predictions are not borne out by empirical work; for further counterexamples see Bowern et al. (2011).

Now, let us consider what changes we expect to see in a population with reduced allophonic diversity. Two outcomes are possible. One is conservatism, and the other is drift. In the first case, the relevant factor is the amount of variation. Variation drives sound change; without variation, there can be no change, since variationless systems leave no room for ambiguity in acquisition, and no room for shift in adults; these are the two primary ways in which change is actuated within a community. Thus communities with less variation would be expected under this model to show slower rates of sound change.

Alternatively, founder populations might show greater amounts of phonetic drift (this is the case in biology as well; small founder populations show greater rates of drift). ${ }^{3}$ At the phonetic level, one way that sound change is actuated is when children acquiring the language extract the significant categories from the information around them. If they are acquiring categories which are modeled by a reduced pool of variation where the cues for a category are biased in some way, this may lead to change. For example, realizations of a vowel /a/ in the original population might vary by $100 \mathrm{~Hz}$ or more in the lower formants. If the founder population is drawn from a subset of the population where realizations of /a/ tended towards the upper range of formant values, this could bias subsequent generations towards a realization which was higher than that of the original population; it may also change the phonemic category of the vowel.

Importantly, however, drift-induced changes are neutral with respect to whether they lead to an increase or decrease in phoneme inventory size. Driftinduced changes depend on the properties of the variation in the founder pop-

3. At the level of a population, this follows automatically from principles of inheritance. If the relative proportions of alleles of a gene change within a population through migration, that will affect the likelihood of inheritance of those alleles in subsequent generations. 
ulation, and may add to, decrease, or simply change the composition of the phoneme inventory (without affecting phoneme numbers). That is, they are stochastic. This is confirmed by studies of founder effects in the formation of new varieties of English over the last few hundred years (Labov 2002, Trudgill et al. 2000, Gordon et al. 2004, Ross et al.1964, Schreier 2009). Thus, in summary, we expect phonetic founder effects to be either neutral or systempreserving at the phonemic level.

\section{Causes of increase or decrease in inventory size}

Correlation, of course, is not causation. Other authors who have noted robust correlations between population size and inventory size (Hay \& Bauer 2007, Trudgill 2004a, b, Maddieson 1986) have noted that there is no straightforward reason why smaller populations should have smaller phoneme inventories. Trudgill (2004a: 306) suggests that the social network structure of small populations leads to the maintenance of rare changes. Conversely, since larger languages have more adult second language learners, they are more likely to show changes which reflect language shift, including the elimination of contrasts which are difficult for second language learners to acquire. Absent from this discussion, however, is an indication of how small linguistic populations would need to be to show such effects, whether there is an absolute threshold, or whether the crucial effect is how large the linguistic community is in relation to its neighbors.

Absent also from discussions which contrast hunter-gatherers with agriculturalists is a recognition that hunter-gatherer groups also differ substantially across the world (see Bowern 2010 for an overview of the relevant literature). Moreover, models that equate simplicity in social structure with phoneme inventory simplicity often overlook the fact that social hierarchies are only one way in which societies may be "complex". Societies with moieties, sections, kin taboos, clans, and other non-hierarchical but nonetheless socially partitioned structures do show evidence of the same types of socially conditioned variation and change which are found in other societies (see Bowern 2008 for more information); Stanford \& Preston (eds.) 2009 includes case studies and discussion.

Hunter-gatherer languages show a great variety of contact conditions, and presumably have always done so. Hunter-gatherer societies differ extensively in their degrees of participation in local trade networks, in their mobility, and the percentages of their communities which are bi- or multi-lingual. Scenarios of change of both Atkinson's and Trudgill's rely crucially on hunter-gatherer societies being fairly homogeneous across the world, behaving in specific ways in contact situations, and in the balance of language learning situations. However, this has never been tested empirically, and the ethnographic literature 
points to considerable diversity in this area. ${ }^{4}$ Bowern et al. (2011) found that in the domain of loan words, for example, small hunter-gatherer groups showed opposite characteristics in North America and Australia, with small groups showing significantly more loans in Australia, but significantly fewer in California and the Great Basin.

\section{Conclusions, and explaining the correlation}

In conclusion, the population size data, the language locations, and the vowel inventories are the result of Holocene expansions and changes. Whatever the underlying causes of such correlations, they do not reflect population expansions from Africa many millennia ago. Phoneme inventories are not reduced in diversity by the mechanisms that apply in genetic founder effects. Such effects are found, however, in phonetic (that is, sub-phonemic) data. The results of a reduction in phonetic diversity are either conservatism (reflecting a more general process that change in smaller populations is slower than that in larger ones) or drift.

Linguistic and biological evolution have many features in common, and including language change in the more general modeling of evolutionary systems will be beneficial to everyone. We have much to learn about the dynamics of linguistic systems and how they are shaped by social and evolutionary processes. In elucidating our linguistic history, modeling and simulations are an important part of the toolkit. We are also in clear need of better data about the sociolinguistics of small hunter-gatherer communities. A model may be a lie that leads to the truth; in this case, however, the truth we are led to is that the origin of language is as tantalizing and as unreachable as ever.

Received: 31 May 2011

Revised: 18 July 2011

Yale University

Correspondence address: Department of Linguistics, Yale University, 370 Temple St, Room 204, PO Box 208366, New Haven CT 06520-8366; U.S.A.; e-mail: claire.bowern@yale.edu

Acknowledgements: This work is funded in part by NSF grant BCS-902114 "Dynamics of huntergatherer language change". I thank Keith Hunley, Erich Round, and the participants of Yale's CLAY lab for discussion of these topics.

4. See amongst others Balée 1994; Rival 1998, 2002; Panter-Brick et al. 2001; Meehan \& White 1990 


\section{Claire Bowern}

\section{References}

Ackerknecht, Erwin H. 1965. History and geography of the most important diseases. New York: Hufner.

Atkinson, Quentin D. 2011. Phonemic diversity supports a serial founder effect model of language expansion from Africa. Science 332. 346-349.

Balée, William. 1994. Footprints of the forest: Ka'apor ethnobotany - The historical ecology of plant utilization by an Amazonian people. New York: Columbia University Press.

Bowern, Claire. 2008. Seven speakers, eight varieties: Variation in an endangered Arnhem Land clan language. Paper presented at New Ways of Analyzing Variation 37, Houston.

Bowern, Claire. 2010. Correlates of language change in hunter-gatherer and other "small" languages. Language and Linguistics Compass 4. 665-679. http://onlinelibrary.wiley.com/doi/ 10.1111/j.1749-818X.2010.00220.x/full

Bowern, Claire, Patience Epps, Russell D. Gray, Jane Hill, Keith Hunley, Patrick McConvell \& Jason Zentz. 2011. Does lateral transmission obscure inheritance in hunter-gatherer languages? PLoS ONE 6(9). e25195. http://www.plosone.org/article/info:doi/10.1371/journal. pone.0025195

Briscoe, Gordon \& Len Smith (eds.). 2002. The Aboriginal population revisited: 70,000 years to the present (Aboriginal History Monograph Series 10). Canberra: Aboriginal History.

Chakraborty, Ranajit \& Masayoshi Nei. 1977. Bottleneck effects on average heterozygosity and genetic distance with the stepwise mutation model. Evolution 31. 347-356.

Choudhury, Monojit, Animesh Mukherjee, Anupam Basu, Niloy Ganguly, Ashish Garg \& Vaibhav Jalan. 2009. Language diversity across the consonant inventories: A study in the framework of complex networks. In Afra Alishahi, Thierry Poibeau \& Aline Villavicencio (eds.), CACLA '09: Proceedings of the EACL 2009 Workshop on Cognitive Aspects of Computational Language Acquisition, 51-58. Stroudsburg, PA: Association for Computational Linguistics. http://portal.acm.org/citation.cfm?id=1572461.1572470

Dorian, Nancy C. 1994. Varieties of variation in a very small place: Social homogeneity, prestige norms, and linguistic variation. Language 70. 631-696.

Garrett, Andrew \& Keith Johnson (forthcoming). Phonetic bias in sound change. In Alan C. L. Yu (ed.), Origins of sound change: Approaches to phonologization. Oxford: Oxford University Press.

Gordon, Elizabeth, Lyle Campbell, Jennifer Hay, Margaret Maclagen, Andrea Sudbury \& Peter Trudgill,. 2004. New Zealand English: Its origins and evolution. Cambridge: Cambridge University Press.

Granovetter, Mark. 1983. The strength of weak ties: A network theory revisited. Sociological Theory $1.201-233$

Gray, Russell D., Alexei J. Drummond \& Simon J. Greenhill. 2009. Language phylogenies reveal expansion pulses and pauses in Pacific settlement. Science 323. 479-483.

Hale, Kenneth L. 1964. Classification of Northen Paman languages, Cape York Peninsula, Australia: A research report. Oceanic Linguistics 3. 248-265.

Hale, Kenneth L. 1976. Phonological developments in particular Northern Paman languages. In Peter Sutton (ed.), Languages of Cape York (Australian Aboriginal Studies, Research and Regional Studies 6), 7-40. Canberra: Australian Institute of Aboriginal Studies.

Haspelmath, Martin, Matthew S. Dryer, David Gil \& Bernard Comrie (eds.). 2008. The world atlas of language structures online. München: Max Planck Digital Library.

Hay, Jennifer \& Laurie Bauer. 2007. Phoneme inventory size and population size. Language 83. 388-400.

Hock, Hans Henrich \& Brian D. Joseph. 1996. Language history, language change, and language relationship: An introduction to historical and comparative linguistics. Berlin: Mouton de Gruyter. 
Holden, Clare Janaki. 2002. Bantu language trees reflect the spread of farming across sub-Saharan Africa: A maximum-parsimony analysis. Proceedings of the Royal Society of London, Series B: Biological Sciences 269(1493). 793-799.

Hunley, Keith, Claire Bowern \& Megan Healy (in preparation). Phoneme inventory size patterned by local exchange, not founder effects out of Africa. Manuscript.

Labov, William. 2001. Principles of linguistic change, Vol. 2: Social factors. Oxford: Blackwell.

Labov, William. 2002. Driving forces in linguistic change. In Sang-Cheol Ahn \& Gregory K. Iverson (eds.), Proceedings of the 2002 International Conference on Korean Linguistics. Seoul: Hankook.

Labov, William. 2007. Transmission and diffusion. Language 83. 344-387.

Lewis, M. Paul (ed.). 2009. Ethnologue: Languages of the world. 16th edn. Dallas: SIL International.

Maddieson, Ian. 1986. The size and structure of phonological inventories: Analysis of UPSID. In John J. Ohala \& Jeri J. Jaeger (eds.), Experimental phonology, 105-123. Orlando, FL: Academic Press.

Mallory, J. P. 1989. In search of the Indo-Europeans: Language, archaeology, and myth. London: Thames \& Hudson.

McConvell, Patrick. 1996. Backtracking to Babel: The chronology of Pama-Nyungan expansion in Australia. Archaeology in Oceania 31. 125-144.

Meehan, Betty \& Neville White. 1990. Hunter-gatherer demography: Past and present (Oceania Monograph 39). Sydney: University of Sydney.

Mielke, Jeff. 2008. The emergence of distinctive features. Oxford: Oxford University Press.

Milroy, James. 1992. Social network and prestige arguments in sociolinguistics. In Kingsley Bolton \& Helen Kwok (eds.), Sociolinguistics today: International perspectives, 146-162. London: Routledge.

Milroy, James \& Lesley Milroy. 1985. Linguistic change, social network and speaker innovation. Journal of Linguistics 21. 339-384.

Milroy, Lesley \& James Milroy. 1992. Social network and social class: Toward an integrated sociolinguistic model. Language in Society 21(1). 1-26.

Nettle, Daniel. 1999. Linguistic diversity. Oxford: Oxford University Press.

Nettle, Daniel. 2000. Linguistic diversity, population spread and time depth. In Colin Renfrew, April McMahon \& Larry Trask (eds.), Time depth in historical linguistics, Vol. 2, 665-677. Cambridge: McDonald Institute for Archaeological Research.

Ohala, John J. 2009. Languages' sound inventories: The devil in the details. In François Pellegrino, Egidio Marsico, Ioana Chitoran \& Christophe Coupé (eds.), Approaches to phonological complexity (Phonology and Phonetics 16), 47-58. Berlin: Mouton de Gruyter.

Panter-Brick, Catherine, Robert H. Layton \& Peter Rowley-Conwy. 2001. Hunter-gatherers: An interdisciplinary perspective. Cambridge: Cambridge University Press.

Rival, Laura M. 1998. Domestication as a historical and symbolic process: Wild gardens and cultivated forests in the Ecuadorian Amazon. In William Balée (ed.), Principles of historical ecology, 232-250. New York: Columbia University Press.

Rival, Laura M. 2002. Trekking through history: The Huaorani of Amazonian Ecuador. New York: Columbia University Press.

Ross, A. S. C. \& A. W. Moverley. 1964. The Pitcairnese language. London: Deutsch.

Schreier, Daniel. 2009. Language in isolation, and its implications for variation and change. Language and Linguistics Compass 3. 682-699. http://onlinelibrary.wiley.com/doi/10.1111/ j.1749-818X.2009.00130.x/full

Stanford, James N. \& Dennis R. Preston (eds.). 2009. Variation in indigenous minority languages. Amsterdam: Benjamins.

Trudgill, Peter. 2004a. Linguistic and social typology: The Austronesian migrations and phoneme inventories. Linguistic Typology 8. 305-320.

Trudgill, Peter. 2004b. On the complexity of simplification. Linguistic Typology 8. 384-388. 
Trudgill, Peter, Elizabeth Gordon, Gillian Lewis \& Margaret Maclagan. 2000. Determinism in new-dialect formation and the genesis of New Zealand English. Journal of Linguistics 36. 299-318. 